\title{
Uterus-Sparing Treatment Options for the Management of Fibroids
}

\author{
Alessandro Napoli ${ }^{1}$, Roberto Scipione ${ }^{1}$, Hans-Peter Erasmus ${ }^{1 *}$, Cristina Marrocchio ${ }^{1}$, Susan \\ Dababou $^{1}$, Fabrizio Andrani ${ }^{1}$, Carola Palla ${ }^{1}$, Michele Anzidei ${ }^{1}$, Federica Ciolina ${ }^{1}$, Lucia \\ Manganaro $^{1}$, Delia Savone ${ }^{2}$, Ludovico Muzii' ${ }^{2}$, Francesco Pecorini² and Carlo Catalano ${ }^{1}$
}

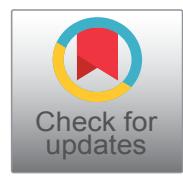

${ }^{1}$ Department of Radiological, Oncological and Pathological Sciences, Policlinico Umberto I, Sapienza University of Rome, Italy

${ }^{2}$ Department of Gynecology-Obstetrics and Urology, Policlinico Umberto I, Sapienza University of Rome, Italy

*Corresponding author: Hans-Peter Erasmus, Department of Radiological, Oncological and Pathological Sciences, Policlinico Umberto I, Sapienza University of Rome, Italy

\begin{abstract}
Currently, different treatment options are available in the management of uterine fibroids: Medical therapy aims at relieving symptoms, while semi-invasive or non-invasive procedures aim to treat symptoms and eventually to reduce the fibroids' size. A wide spectrum of treatments may be confusing to implement correctly, and the gynecologist should be familiar with the features of each procedure, to provide a personalized therapy, with each patient being directed towards the most suitable therapeutic option according to her specific characteristics. A thorough knowledge of the properties of each therapeutic strategy is fundamental for a correct orientation of the specialist in the management of symptomatic uterine fibroids; the final purpose has to be the establishment of an individual-centered care system, within each woman will be addressed by the most suitable among the available treatment options. This work provides a panoramic view of the main available uterus-sparing strategies for the management of symptomatic fibroids (with particular attention on specific indications, patient selection, advantages and adverse events), as well as a practical and comprehensive guide for the choice of the most appropriate option.
\end{abstract}

\section{Keywords}

Uterine fibroid, Uterine myoma, High intensity focused ultrasound, Uterine artery embolization, Myomectomy

\section{Introduction}

Currently, symptomatic uterine fibroids can be managed with a wide array of different strategies. The gynecologist has a vast choice among consolidated therapies, and additional innovative procedures are emerging as valuable alternatives.
This scenario may be, sometimes, confusing; a common misconception is to consider these treatments as exclusive competitors in contrast with each other: On the contrary, they should be regarded as alternative therapeutic options with specific strengths and shortcomings, and the gynecologist should be familiar with the characteristics of each one, in order to provide a personalized therapy.

The purpose of this work is to describe the main available uterus-sparing strategies for the management of symptomatic fibroids, as well as to provide a practical guide for the choice of the most appropriate option.

\section{Background}

Historically, the most established uterus-sparing techniques are on the extremes of the spectrum of invasiveness: on one hand, there is medical therapy; on the other, there is surgical abdominal/laparoscopic myomectomy. Between these two extremes there is the minimally invasive hysteroscopic resection. A general description of these three main pillars of treatment will be provided in this section, including the main characteristics and the eligibility criteria of each one. The grade of evidence will be presented for some of these procedures from highest (grade A) to lowest (grade C), with the highest grade presented by large randomized controlled trials and the lowest small observational studies and the like.

\section{Medical Therapy}

Currently, available medical treatments cannot make 
fibroids disappear (LE1); therefore, there is no need for medical therapy in case of asymptomatic patients (grade A) [1].

In the management of symptomatic fibroids, medical treatments usually aim for a short-term control of symptoms because of the risks related to long-term therapy and the lack of evidence about the balance between benefits and risks in prolonged treatments.

The most commonly used agents are gonadotropin-releasing hormone analogues ( $\mathrm{GnRHa}$ ) and the selective progesterone receptor modulators (SPRMs). However, a huge variety of medications has been proposed as alternative, such as levonorgestrel intrauterine device (LNg-IUD) [2], selective estrogen receptor modulators (SERMs) [3], combined oral contraceptive and progestins [4], aromatase inhibitors [5], somatostatin analogues [6], androgenic agents (gestrinone and danazol) $[7,8]$, tranexemic acid [9], antifibrotic factors (vitamin D and epigallocatechin gallate) $[10,11]$. In addition to these treatments, more research is being performed to find and evaluate new potential and promising medications. Main features of medical therapy are summarized in Table 1.

\section{Selection of patients}

The clinical management of fibroids has to consider the individual characteristics of each patient and requires meticulous previous counseling: Factors as age, type and severity of symptoms, and the desire for future pregnancies should always be evaluated before starting any treatment.

Medical therapy is generally used as a 'stand-alone' treatment to obtain a temporary relief of symptoms for short periods. Women in peri-menopausal age represent the most ideal category of patients. In fact, fibroids are hormonally-responsive and tend to regress independently after the natural cessation of steroid hormone exposure; thus, medical therapy can be safely used during the short period that precedes menopause, relieving symptoms until they naturally disappear. The same principle can be applied to women scheduled for surgery: medical therapy is useful in the pre-operative period to control symptoms, improve hemoglobin $(\mathrm{Hb})$ levels and reduce the size of fibroids. In this way, it is possible to reduce operative time and often to allow for a laparoscopic approach instead of an open one. After the intervention, medical therapy is no longer needed and the patient can be dismissed.

Patients not suitable for surgery may also be managed with medical treatment. For example, women with contextual polycystic ovary syndrome or endometriosis may take a benefit from medical therapy for these associated conditions as well. However, due to increasingly brilliant results of non- and semi-invasive interventional approaches, patients not suitable for surgery are currently guided towards these techniques rather than medical treatment, because the specific inclusion criteria are usually attained.

\section{GnRH analogs}

GnRHa have been approved by the FDA as safe and effective in reducing fibroid size and in relieving symptoms, representing the most common medical treatment in fibroid management; Lupron Depot (leuprolide acetate) was the first medical treatment ever approved by the FDA for the treatment of fibroids.

The analogs have a similar structure to $\mathrm{GnRH}$ and can bind the same receptor, but have a greater and longer biological effect. A single injection of $\mathrm{GnRHa}$ produces an initial stimulation of pituitary gonadotropins, resulting in an increased secretion of follicle-stimulating hormone (FSH) and luteinizing hormone (LH), with the expected gonadal response and consequent central down-regulation (drug-induced menopause, with a hypogonadotropic hypogonadal state) [12]. On fibroid tissue, the effect consists in an increased apoptosis and a decrease in both angiogenesis and inflammatory reaction [13].

GnRHa have shown to induce fibroid shrinkage and decrease of tumor-related symptoms [14,15]. The therapeutic effect has shown to be comparable to the decrease of estrogen levels [16] and is directly proportional to the percentage of cells that express the ER receptor [17]. However, the studies have shown that the beneficial effects are limited to short periods of treatment (usually 3 or 6 months), after which a rebound effect occurs: the mass grows to reach pre-treatment size again $[18,19]$.

It has been reported that the use of GnRHa prior to surgery determines an improvement in $\mathrm{Hb}$ and hemato-

Table 1: Summary of medical therapy main features.

\begin{tabular}{|l|l|l|}
\hline Medical therapy & \multicolumn{2}{l|}{} \\
\hline Indications & Short-term control of symptoms in symptomatic women. \\
\hline Suitable patients & $\begin{array}{l}\text { Women in perimenopausal age, women scheduled for surgery, patients not suitable for surgery because of } \\
\text { contextual medical reasons. }\end{array}$ & SPRMs \\
\hline Advantages & GnRHa & $\begin{array}{l}\text { Absence of estrogen deficiency effect; long-lasting effect/ } \\
\text { Prolonged therapy without menopausal symptoms. }\end{array}$ \\
\hline Adverse events & $\begin{array}{l}\text { Good symptom relief for limited periods. } \\
\text { - Transient/Rebound Effect. }\end{array}$ & $\begin{array}{l}\text { Mifepristone: } \\
\text { - Endometrial Hyperplasia. }\end{array}$ \\
\hline
\end{tabular}

GnRHa: Gonadotropin Releasing Hormone analog; SPRM: Selective Progesterone Receptor Modulator. 
crit ( $\mathrm{Htc}$ ) levels, a shrinkage of the uterus and the fibroid volume, a reduction of symptoms and operating time, a more frequent laparoscopic approach rather than open surgery and a minor duration of hospitalization after surgery [20].

The greatest disadvantages of GnRHa include their costs, their transient effect, menopausal symptoms, and (for prolonged therapy) bone demineralization. The latter represents the most critical adverse event that prohibits longer treatment periods. However, an add-back therapy has been proposed as a strategy to reduce the side effects during GnRHa treatment. Agents like progestins and estrogens, alone or combined, have shown to reduce adverse events without any loss in therapeutic effectiveness [19].

\section{Selective Progesterone Receptor Modulators (SPRMs)}

The role of progesterone and the progesterone receptor in the proliferation of fibroid cells has been widely demonstrated [21]. Therefore, SPRMs have been investigated as a therapeutic option.

SPRMs induce apoptosis and decrease cell proliferation through the inhibition of the effects of progesterone on the neoplastic tissue, turning off the fibroid growth [22].

The first drugs to be studied were Mifepristone and Asoprisnil: They both showed to be effective in reducing fibroid mass size and associated symptoms [23]. Lately, ulipristal acetate (UPA) showed its effectiveness and safety and was approved for fibroid medical management [24]. It appears to have few serious (functional ovarian cysts, uterine hemorrhage and thickening of the endometrial lining that reverses when discontinuing treatment) and some minor (most frequently hot flushes, breast pain and headaches) side effects that appear reduced with repeated courses and is not recommended for patients with moderate and severe hepatic impairment. Following seven cases of severe liver impairment causing four liver transplantations (causality uncertain in some of these cases), the European Medicines Agency has started a review on UPA to determine any serious risks that have, until now, fallen under the radar [25]. Considering the symptomatic and not curative effect of UPA, the Pharmacovigilance Risk Assessment Committee has concluded to provisionally limit the use of UPA to patients currently under treatment and monitor their serum transaminase level at least monthly and immediately in case of signs or symptoms of liver injury. Serum levels of two times the upper limit of normal should be considered as the threshold in which the discontinuation of treatment is recommended [26].

As SPRMs do not lead to estrogen deficiency, a decrease in bone mineral density as observed in GnRHa therapy is not a problem; they are associated with a reduction of pain, bleeding and size of fibroids, providing an overall improvement in quality of life [23]. For these reasons, GnRHa have been proposed as the better choice for pre-operative "bridge" treatment. Moreover, their therapeutic effect seems to be longer than GnRHa after treatment interruption [27].

Initial studies with Mifepristone showed that its use was limited because of the effects on endometrial tissue (hyperplasia), especially when administered for more than 3 months [28]. A combination of mifepristone and the LNg-IUD could prove especially useful as the IUD would avoid development of endometrial hyperplasia while also promoting a reduction in menstrual flow.

\section{Other Medical Therapies}

Antifibrinolytic agents: Tranexamic acid is a synthetic antifibrinolytic drug that is often used as first-line therapy for symptomatic relief. Fibrinolysis contributes to fibroid-related bleeding and use of tranexamic acid was shown to reduce menstrual blood flow and improve quality of life without any effect on fibroid size $[9,29,30]$. Tranexamic acid is well-tolerated with a favourable safety $[9,29]$. Initially, there were concerns about a possibly increased risk of venous thromboembolism due to its mechanism of action, but this has not been observed in clinical 1 [9]. It should not be associated with oral contraceptives [31].

Levonorgestrel-releasing intrauterine device (LNGIUD): This intrauterine device reduces menorrhagia and increases the hematocrit, hemoglobin, and ferritin serum level of patients [32-34]. Compared to combined oral contraceptives, the LNG-IUD significantly reduces the menstrual blood loss $(90.9 \%$ vs. $13.4 \% \mathrm{p}<0.001)$ [35]. The effect on fibroid size is more controversial. Even though the released progesterone would be expected to increase fibroid size, size remained constant or even decreased in some studies [36-38]. Being a local treatment, the side effects are minimal; the most common ones are irregular bleeding and ovarian cysts which resolve spontaneously over time [39]. Apart from ovarian cysts, no other adverse effects on ovarian function have been noted [38]. Concerns have been about the long-term cardiovascular effects of levonorgestrel, but this requires further study [40].

Once inserted, the effects last 5 years. This has numerous advantages in terms of costs and patient compliance. Due to a higher risk of IUD expulsion, it should not be implanted in patients with endometrial distortions [34] currently there are no studies studying the correlation of expulsion rates with specific fibroid positions.

Combined oral contraceptives: Epidemiologic studies suggest that combined oral contraceptives reduce fibroid-related heavy menstrual bleeding with no effect on their size $[30,41]$. A randomized controlled trial showed that they are efficient, but less so than LNG-IUD [35].

Though initially considered to be a contraindication 
for the use of combined oral contraceptives due to the potential risk of fibroid growth, a recent metanalysis suggests that uterine fibroids should not be considered a contraindication for their use [41].

Progestin: There is only low-quality evidence of their efficacy, with clinical trials reporting mixed results. To date, some studies showed a tendency for improvement of bleeding and reduction of fibroid size using depot medroxyprogesterone acetate (DMPA) [42,43]; some noted a recurrence after or even significant growth during treatment $[44,45]$. Overall larger, better designed studies are needed to gain conclusive results about the efficacy and risks of progestins.

Aromatase inhibitors: Uterine fibroids show a high expression of aromatase, especially in African-American women $[46,47]$. Therefore, its inhibition may have a significant effect on the hormone-dependent fibroid growth. The reduction of uterine volume induced by aromatase inhibitors is comparable to $\mathrm{GnRH}$ analogues [48]. Side effects are usually mild, the most common being hot flushes, vaginal dryness, and musculoskeletal pain. With long-term use, hypoestrogenemia, loss of bone mineralisation and increased risk of bone fractures may also be found [49]. A Cochrane review in 2013 concluded that the evidence of the efficacy and safety of aromatase inhibitors for the treatment of uterine fibroids is still not sufficient [5]. Therefore, further studies are needed before these agents can be recommended.

SERMs: Tamoxifen was compared to placebo for the treatment of symptomatic uterine fibroids. Even if it resulted in reduced bleeding, the side effects of this therapy outweigh the benefits and cannot be recommended [50]. A Cochrane review analyzing three studies using Raloxifene for the treatment of uterine fibroids concluded that the efficacy of treatment is not clear and larger randomized controlled trials are needed before recommending this agent [51].

Somatostatin analogues: In 2001, De Leo, et al. evaluated the efficacy of Lanreotide in seven women with satisfactory outcome ( $24 \%$ total uterus volume and $42 \%$ myoma reduction over the course of 3 months) [6]. The study demonstrated important evidence suggesting an involvement of growth hormones in the pathophysiology of uterine fibroids. No further clinical studies have been conducted.

Androgenic agents: Danazol and Gestrinone seem to be efficient for controlling some of the fibroid-related symptoms in the short term. Nevertheless, due to the higher rate of side effects and the lack of reliable evidence from large randomized controlled trials on their benefit or harm, they cannot be currently recommended [40].

\section{Myomectomy}

Myomectomy is a uterus-preserving surgical procedure that combines an effective local treatment with low morbidity rates. Because of its "partially invasive" nature, it is considered as the standard surgical procedure for women with the desire for future pregnancies.

The first description of an abdominal laparotomic myomectomy dates back to the 1930's [52], while the laparoscopic approach was introduced at the end of the 70's [53]. Open myomectomy requires a large (about 12-cm long) transverse incision of the abdominal wall, with large superficial sutures once the fibroid is removed; on the contrary, laparoscopy uses tiny keyhole incisions through which operative instruments are introduced and resected masses are excised. Mini-laparotomy and laparoscopically-assisted mini-laparotomy are other emerging procedures: they can be considered to be open surgery techniques, while requiring only a minimal access (5-cm-long incision).

Overall, laparoscopic myomectomy has proven clear benefits and is currently the dominant technique, ensuring a lower traumatic impact, shorter hospital recovery times, lower analgesic doses used and a faster return to daily activities [54]. Laparoscopic surgery has shown an average full recovery time of $10.58 \pm 6.68$ days [55] and the results about quality of life in women who underwent this technique are comparable to Uterine Artery Embolization (UAE) [56]. Clinical benefits are stable in time, even though the recurrence rate is not negligible: A 2007 study examined treated women with trans-vaginal ultrasonography and showed that the recurrence rate steadily increases from $11.7 \%$ to $36 \%$ to $53 \%$ at one, three and five years of follow-up, respectively [57]. Nonetheless, it is estimated that re-treatment is required only in about $37 \%$ of recurrences [58].

The most predominant aspect of myomectomy is represented by its impact on reproductive outcomes: $A$ prospective cohort described a pregnancy rate of $70 \%$ in treated women with desire to conceive [59]. According to another study, post-myomectomy pregnancy rates are higher in women who do not have additional infertility factors. These results suggest that the removal of fibroids benefits especially patients with infertility due to an otherwise unknown cause: Surgery should be strongly recommended for these patients [60]. The most controversial issue is referred to intramural fibroids not distorting the endometrial cavity: in this case there is a clear reduction in benefits rates and an increase in miscarriage rates [61]. Available data are still insufficient to understand if the myomectomy is the most appropriate kind of treatment for these patients.

The most common postoperative complications are wound infection, fever, urinary tract infection and ileus. Adhesions may contribute to pain, intestinal occlusion and infertility. Major complications are represented by unscheduled returns to the operating theatre because of ileal perforation and diffuse peritonitis. Rare cases of uterine rupture in subsequent pregnancies have been described. 
Table 2: Summary of myomectomy main features.

\begin{tabular}{|c|c|c|}
\hline \multicolumn{3}{|c|}{ Laparotomic/Laparoscopic myomectomy } \\
\hline Indications & \multicolumn{2}{|c|}{$\begin{array}{l}\text { Stable and effective control of symptoms and mass removal in symptomatic women with a wish for future } \\
\text { pregnancies. }\end{array}$} \\
\hline \multirow[t]{2}{*}{ Selection } & \multicolumn{2}{|c|}{$\begin{array}{l}\text { Subserosal fibroids/intramural fibroids protruding into the uterine cavity no more than than } 50 \% \text { of their size. } \\
\text { Wide selection in patients not suitable for non-invasive procedures. }\end{array}$} \\
\hline & Myomectomy & Laparoscopy over laparotomy \\
\hline Advantages & $\begin{array}{l}\text { - Effective. } \\
\text { - Well tolerated (good QoL). } \\
\text { - Good fertility potentials. }\end{array}$ & $\begin{array}{l}\text { - Lower traumatic impact. } \\
\text { - Shorter hospital recovery time. } \\
\text { - Lower analgesic dose. } \\
\text { - Faster return to daily activities. }\end{array}$ \\
\hline Adverse events & $\begin{array}{l}\text { - Invasive surgical procedure (even if the invasive- } \\
\text { ness has different degrees). } \\
\text { - Recurrences increasing during postoperative years. } \\
\text { - Postoperative complications (infection, fever, uri- } \\
\text { nary tract infection, ileus, adhesions, diffuse peritoni- } \\
\text { tis) - Heavier in laparotomic approach. } \\
\text { - Uterine rupture. }\end{array}$ & - Malignant cells spreading during power morcellation. \\
\hline
\end{tabular}

QoL: Quality of Life.

Overall, a laparoscopic approach has shown a lower postoperative complication rate than open surgery [62]. Another controversial aspect is represented by electromechanical morcellation. Its introduction has allowed the technical exportation of voluminous resected masses through the tiny laparoscopic door, extending myomectomy up to even the largest fibroids; however, it has been suggested that power morcellation may cause seeding of inner degenerative leiomyosarcoma cells into the abdominal and pelvic cavity, with a serious aggravation of life expectancy [63]. For that reason, in 2014 the FDA discouraged the use of power morcellation in the laparoscopic treatment of fibroids and recommended that every operator in the U.S. informs patients of potential risks when the use of this technique is unavoidable. Currently, the main orientation to overcome this risk is towards the use of the isolation sack, or mini-laparotomic approach. The main features of myomectomy are summarized in Table 2.

\section{Selection of patients}

Despite the introduction of innovative and sophisticated non-invasive treatments, surgery remains a fundamental solution, in particular for women with large or symptomatic fibroids [64].

The inclusion criteria initially proposed for laparoscopic surgery were: $A$ uterine size less than or equal to 14 weeks of gestation after 12 weeks of gonadotropin-releasing hormone (GnRH) agonist therapy; no individual fibroid larger than $7 \mathrm{~cm}$; no fibroid near the uterine artery or the tubal cornua if fertility was desired; and at least $50 \%$ of the fibroid to be subserosal to be accessible and to allow adequate repair of the myometrium through the laparoscope [65]. Through technical improvement (e.g., power morcellation has allowed to successfully [66] remove $20 \mathrm{~cm}$-large fibroids), most of the initial limitations have been overcome. Neverthe- less, the localization of fibroids in the layers of uterine wall remains a key-factor for the choice of intervention access: while intracavitary fibroids can be removed by hysteroscopic access, intramural and subserosal lesions are usually removed through open or laparoscopic myomectomy.

Myomectomy is the technique of choice and currently doesn't present very strict inclusion criteria, being suitable in a wide range of patients. Therefore, it is employed as a "safety net" in our algorithm, offered to all those patients that cannot undergo non-invasive procedures such as UAE or MR-guided focused ultrasound (MRgFUS). In particular, myomectomy guarantees optimal results in women seeking a stable and lasting effect (hence, excluding medical therapy as an option), with features that do not meet the requirements for MRgFUS treatment and who have a desire for future pregnancies (thus wanting to avoid UAE). However, in this decisional process, a previous counseling is essential, so that eligible patients can be informed about the risk of symptoms persisting and that the fibroids may recur and require further surgery (grade A) [1].

\section{Leiomyomatosis peritonealis disseminata}

One uncommon disease that should be noted here is leiomyomatosis peritonealis disseminata (LPD). Though to date only about 150 cases have been noted, the rate of reporting seems to be increasing after laparoscopic myomectomy; this has led to propose morcellation and myoma fragment scattering around the abdominal cavity as a mechanism $[67,68]$. Though usually of benign course, in rare cases malignant transformation may occur and may thus be reason for revaluation of some morcellation techniques, though larger studies will be needed to properly assess their risk in this new light and the overall morbidity and mortality of LPD [59]. Presently, the only offered solution is the use of 
an endoscopic bag that appears promising [60]; some challenges are that this requires advanced laparoscopic skills to prevent complications and worsens the visualization of structures. In 2015, the European Society of Gastrointestinal Endoscopy proposed an algorithm to help deciding for or against morcellation based on the characteristics of fibroids to avoid treatment of an occult sarcoma [61].

\section{Hysteroscopic Resection}

A simple, well tolerated and effective procedure, hysteroscopic resection is a variant of myomectomy that removes submucosal fibroids through the cervix. During a hysteroscopic myomectomy, an endoscope is inserted through the cervix and fibroids extruding into the endometrial cavity are removed with electrosurgical (thermal loops and vaporizing electrodes) and mechanical instruments (cold loops). An intrauterine morcellator may also be used to perform the procedure.

This technique is discussed separately from myomectomy because it differs markedly from the traditional open/laparoscopic approach and spares the abdominal wall from any incision; thusly, the benefits of laparoscopic myomectomy are further enhanced: shorter recovery times (about 8 hours), lower postoperative pain, faster return to normal activities, lower risk of complications, no cosmetic damage. The salient features of hysteroscopic resection are summarized in Table 3.

\section{Selection of patients}

The International Federation of Gynecology and Obstetrics identifies three subtypes of submucosal myomas depending on the proportion of fibroid within the myometrium: A type 0 myoma is located entirely out of the myometrium, type 1 and 2 lie within it less or more than $50 \%$, respectively [69]. Hysteroscopic myomectomy is particularly suited for symptomatic submucous fibroids in women who wish to maintain their fertility. Type 0-1 fibroids up to $5 \mathrm{~cm}$ and type 2 myomas up to $4 \mathrm{~cm}$ can be removed safely (though it is possible to treat lesions of $4-6 \mathrm{~cm})[70,71]$. It has been shown to be a safe and cost-effective approach resulting in high patient satisfaction [61]. The thickness of residual myometrium wall just above the serosa should be measured and shouldn't be less than $5 \mathrm{~mm}$ to avoid complications: this way, the risk of rupture of the gravid uterus after the intervention is negligible.

\section{Techniques}

The intervention itself is performed by using bipolar resectoscopes, hysteroscopic morcellation, or hybrids. Bipolar resectoscopes are equipped with U-shaped wire electrodes at the tip of their sheat that use cutting currents to remove strips of the fibroid with each pass. Hemostasis can be achieved with activation of intermittent or coagulation current. The removed tissue fragments are then extracted by hooking with the resectoscope wire or blind removal with polyp forceps. Hybrids add an automatic tissue aspirator to this setup. Hysteroscopic morcellators operate via mechanical, sequential and progressive morcellation of the fibroid. They are composed of a cylindrical blade within a windowed sheath to allow for precise tissue removal. The tissue fragments are aspirated via an integrated suction device [72].

Optimal benefits are referred to heavy menstrual bleeding and infertility, while other conditions are not so favorable, even though they can be improved by previous treatment with $\mathrm{GnRHa}$.

\section{Uterine Artery Embolization (UAE)}

First described by Ravina, et al. in 1995 [73], UAE is a minimally invasive angiographic percutaneous technique, consisting in the occlusion of the end branches of uterine arteries with embolic particles; it induces ischemic necrosis and subsequent shrinkage of uterine fibroids, leaving the rest of myometrium able to recover and develop collateral supply $[74,75]$. UAE is considered as a global procedure, treating all fibroids at the same time, without the opportunity to specifically select the dominant tumor responsible for symptoms [32].

Table 3: Summary of hysteroscopic resection main features.

\section{Hysteroscopic myomectomy}

Indications Stable and effective control of symptoms and mass removal in symptomatic women wishing to attain future pregnancies.

Selection $\quad$ Submucosal fibroids/Intramural fibroids protruding into the uterine cavity more than $50 \%$. Lesions with diameter $<4 \mathrm{~cm}$.

\begin{tabular}{|l|l|l}
\hline Advantages & Myomectomy: & Hysteroscopy over Laparoscopy and \\
& - Effective. & Laparotomy: \\
& - Well tolerated (good QoL). & - Lower traumatic impact. \\
- Good fertility potentials. & - Shorter recovery time. \\
& - Lower analgesic dose. \\
& - Faster return to daily activities. \\
& - No cutaneous scar. \\
& - Lower risk of complications.
\end{tabular}

Adverse Events Because of the minimally invasive nature of the procedures, adverse events of myomectomy are very rare and of little impact. 
Table 4: Fibroid and anatomical characteristics to consider when preferring UAE to other options.

\begin{tabular}{|c|c|c|}
\hline & Fibroid characteristics & Anatomical considerations \\
\hline Non-responsive & $\begin{array}{l}\text { Fibroids not enhancing on contrast MRI: Are already } \\
\text { degenerated and will not be affected by embolization }\end{array}$ & \multirow{5}{*}{$\begin{array}{l}\text { Individualized decision based on single patient, } \\
\text { e.g. a common arterial supply to ovaries and uterus } \\
\text { that does not allow a selective embolization of the } \\
\text { fibroids sparing the ovaries. }\end{array}$} \\
\hline \multirow{4}{*}{ Less responsive } & Broad ligament fibroids & \\
\hline & $\begin{array}{l}\text { Cervical fibroids, for the possible collateral flow from } \\
\text { the cervical blood supply }\end{array}$ & \\
\hline & $\begin{array}{l}\text { Pedunculated subserosal fibroids if stalk diameter is } \\
\text { at least } 50 \% \text { narrower than the diameter of the tumor }\end{array}$ & \\
\hline & Intracavitary fibroids & \\
\hline
\end{tabular}

\section{Selection of patients}

Selection of patients is a fundamental process to minimize the risk of treatment failure and the need of further interventions [76]. UAE should be preferred to other procedures when specific anatomical characteristics and tumor features are met (Table 4).

UAE is indicated for the treatment of symptomatic uterine fibroids in women who do not wish future fertility but want to avoid surgical procedures or have contraindications to surgery [41].

Absolute contraindications are: pregnancy, active uterine infection, and gynecological malignancies [77]. Relative contraindications are: contrast material allergy, coagulopathy and renal failure $[75,77]$.

Despite initial studies, recent evidence suggests that there are no differences in the results and complication rates for treatment of very large fibroids [78,79]. AAGL guidelines advise for some caution when using UAE in submucosal fibroids due to a possibly increased risk of complications [80]. French guidelines do not recommend UAE for the treatment of a single submucosal intracavitary fibroid (type 0 and 1 ) nor a single subserosal pedunculated fibroid (grade $\mathrm{C}$ ) because of the risk of possible complications [1]. The presence of an IUD has been considered a relative contraindication, but a recent study found no difference in infectious complications with or without the IUD in place [77]. Given that the impact of UAE on future pregnancies is not fully known, it is currently not recommended as a first line treatment in women desiring future fertility; it can be carefully considered in those cases when fertility is desired, but myomectomy is contraindicated $[1,77]$.

\section{Procedure}

Before treatment, patients undergo a gynecological visit including a thorough medical history and physical examination $[74,75,77]$. Trans-abdominal or trans-vaginal US can establish the diagnosis, but MRI allows to better characterize the fibroids. Anatomical variations being common, important aspects to evaluate are the shape, size, signal intensity, anatomical location, and assessment of the exact vascularization [74,77]; mandatory laboratory tests include a complete blood cell count, coagulation studies, a metabolic panel and a pregnancy test $[74,77]$.
UAE procedures last 30-90 minutes, on average [81]. An IV access is obtained and medications are administered for pain and nausea prophylaxis. The insertion of a Foley catheter and administration of prophylactic antibiotic coverage are not recommended [77,81].

During the procedure, the patient is under conscious sedation or local anesthetic; vital functions are monitored [81]. The standard procedure requires overnight hospitalization [81].

After treatment, fatigue is common [82,83]; most patients experience moderate to severe ischemic pain, decreasing after $12 \mathrm{~h}$ and usually resolving within one week [83]: It is easily controlled with NSAIDs and intravenous patient-controlled analgesia, but epidural anesthesia may be required [77]. A rather common cluster of symptoms referred to as "post-embolic syndrome" sometimes occurs within the first day, including pelvic pain, nausea, vomiting, malaise, loss of appetite and low-grade fever $[82,83]$. It is managed with NSAIDs and, unless complications occur, lasts for less than one week [77]. Some menstrual irregularities, spotting and light vaginal bleeding can occur, but within 2-3 months the menstrual cycle should return normal $[74,84]$. Patients can generally return to normal activities within 8-14 days [41]. A follow-up visit is done about six months after the procedure [77].

\section{Complications}

Complications can be immediate (periprocedural), early (within 30 days) or late (after 30 days) (Table 5) [81]. The FIBROID registry reported a rate of $0.66 \%$ and $4.8 \%$ for in-hospital and 30-day major complications, respectively, but most complications occur as late events [82].

Immediate complications are uncommon: non-target embolization should not occur if the procedure is adequately performed, though sometimes uterine-ovarian artery anastomoses may not be immediately evident [77].

Among early complications, vaginal discharge is common; post-embolic syndrome is considered as a complication in the $3-5 \%$ of patients experiencing symptoms severe enough to require rehospitalization [81]; deep vein thrombosis and pulmonary embolism due to a generalized state of hypercoagulability after the procedure are severe but rare occurrences $[75,77]$. 
Table 5: Classification of main complications related to UAE procedure.

\begin{tabular}{|c|c|c|c|}
\hline & Timing & & \\
\hline \multirow{7}{*}{$\begin{array}{l}\text { UAE Compli- } \\
\text { cations }\end{array}$} & Immediate & Early & Late \\
\hline & $\begin{array}{l}\text { Puncturing of femoral artery: } \\
\text { Hematoma, thrombosis, } \\
\text { pseudoaneurysm, rarely failure to } \\
\text { cannulate the artery }\end{array}$ & \multirow[t]{2}{*}{$\begin{array}{l}\text { Vaginal discharge: resolves } \\
\text { spontaneously, but requires treatment } \\
\text { if foul smelling and purulent, } \\
\text { suggesting infection. }\end{array}$} & $\begin{array}{l}\text { Fibroid expulsion (10\%): Expectant } \\
\text { management, but if the fibroid is } \\
\text { very large surgical intervention may } \\
\text { be required. }\end{array}$ \\
\hline & Contrast reaction: Allergic reactions & & Changes in sexual function \\
\hline & \multirow[t]{4}{*}{ Non-target embolization } & Complicated Post Embolic Syndrome & $\begin{array}{l}\text { Endometritis }(0.5 \%) \text { : usually } \\
\text { responds well to antibiotics. }\end{array}$ \\
\hline & & DVT and pulmonary embolism $(<1 \%)$ & Chronic vaginal discharge \\
\hline & & \multirow[t]{2}{*}{ UTI (very rare) } & Amenorrhea \\
\hline & & & Non-target embolization \\
\hline
\end{tabular}

DVT: Deep Venous Thrombosis; UAE: Uterine Artery Embolization; UTI: Urinary Tract Infection.

Among late complications, fibroid expulsion associated with pelvic pain and vaginal discharge may occur, more commonly with submucosal fibroids [82]; amenorrhea ensues in $7.3 \%$ of patients, even if lower percentages were reported in some studies, and represents a considerable issue in patients of fertile age $[77,85,86]$. This may result from non-target embolization to the ovaries and is related to age, being more common in perimenopausal women ( $86 \%$ of cases were patients 45 years or older) [85]. It is transient but may be permanent in fewer than $2 \%$ of patients, more commonly at older age $[77,86]$. Other non-target embolic complications are very rare when performed by a skilled operator [81]. Four cases of death following UAE have been reported: One from pulmonary embolism, one from non-target embolization leading to multi-system infarction, and two following uterine necrosis and sepsis with multiorgan system failure [87-90].

\section{Outcomes}

The clinical success of the procedure is defined by the complete resolution or a satisfactory improvement of symptoms without any additional therapy [77]. At one year after the procedure, $80 \%-90 \%$ of patients were successfully treated, and at $5-7$ years $75 \%$ have persistent effects $[1,81]$. At 6 months the reduction in uterine volume and the dominant fibroid are $30 \%-60 \%$ and $50 \%-80 \%$, respectively [1].

A Cochrane meta-analysis comparing UAE to medical and surgical therapies concluded that embolization is comparable to surgery in terms of patients' satisfaction and complications rate at 2 and 5 years, and in terms of costs at 5 years. UAE has more minor complications and a higher reintervention rate but shorter treatment times, hospital stays, recovery times, and blood transfusion requirements. There is some evidence that myomectomy may be associated to a better fertility outcome, but only few studies addressed this topic [76]. Therefore, UAE is a valid alternative to surgery but the selection of patients is paramount to reduce the need for further interventions to a minimum.

The REST and EMMY trials compared UAE and laparoscopic hysterectomy in terms of quality of life (QoL) and clinical efficacy, and the HOPEFUL study compared the cost effectiveness of UAE to hysterectomy. UAE is superior for its shorter procedure times, lower procedure costs and due to shorter periods necessary to resume normal activities; the drawbacks are its higher reintervention rate, rehospitalization rate and follow-up visits that on the long term ( 5 years) make the cost of the two procedures comparable [91-93]. The efficacy on symptoms and satisfaction of the procedure are comparable at 12 and 24 months, as is the QoL, that remains comparable at 5 years. Hysterectomy has a higher rate of major intraoperative complications and causes more intense pain in the 24 hours following the procedure, while minor intraoperative complications are higher for UAE. The rate of major complications remains higher for surgery for up to 6 months, while UAE reaches similar rates after one year.

The FUME trial comparing UAE to myomectomy evidenced that both procedures result in a significant and comparable improvement in QoL. UAE results in shorter hospital stay and less major complications but has higher reintervention rates [94].

Radiation exposure represents a concern because of the age of patients and the vicinity of the ovaries. When considering radiation dose in balancing risks and benefits of UAE vs. other surgical procedures, UAE is justified if all available techniques to decrease the dose to a minimum are employed [95]. In this case, the total radiation dose (highly variable among studies) can be similar to routine diagnostic procedures [82]. Factors influencing the overall exposure are: experience of the operator, number of projections, collimators' characteristics, and frequency of images acquisition. Pulsed fluoroscopy is recommended over continuous fluoroscopy, and the new generation flat panel devices can reduce the radiation dose by five times when compared to Digital Subtraction Angiography [77].

Successful pregnancies after UAE have been reported. Concerns remain surrounding the risk of amenorrhea and possible effects on embryo implantation and complications during pregnancy, fetal development and delivery. The aim of the ongoing FEMME trial is to compare specifically myomectomy and UAE in terms 
of fertility outcome [96]. Some studies yet to be confirmed favor myomectomy over UAE for short-term fertility [76]. Current evidence suggests that the number of conceptions and term pregnancies are higher and the miscarriage rate is lower after myomectomy rather than UAE [97]. No differences in other pregnancy parameters have been observed, namely preterm deliveries, cesarean section rate, intrauterine growth restriction and postpartum hemorrhage [1]. An impact on ovarian reserve may equally occur in UAE hysterectomy and myomectomy $[98,99]$. In the long term (> 12 months), ovarian reserve may be lower in patients treated with UAE rather than laparoscopic myomectomy, as evidenced by comparable FSH and estradiol levels but higher serum anti-Müllerian hormone levels and a higher number of antral follicles following the surgery [99]; however, longer-term effects of UAE on fertility have yet to be evaluated.

\section{MRI-guided Focused Ultrasound (MRgFUS)}

MRgFUS is a recent non-invasive approach in the management of uterine fibroids. Hereby, mechanical energy is carried by high-intensity ultrasound beams originating from a source outside the patient and focusing on an internal target volume, without any need for skin cuts or invasive interventions. The interaction between ultrasound waves and biological tissues induces the heating and coagulative necrosis of cells, determining a selective thermal ablation of target lesions [100-102]. Concomitantly, real-time control with MRI thermometric map ensures a complete and effective treatment and the sparing of surrounding healthy tissues from any potentially unwanted damage [103].

The use of MRgFUS for the treatment of uterine fibroids has been approved by the FDA in 2004. Currently, there are two FDA-approved MRgFUS systems: The ExAblate 2000 and the ExAblate 2100 (InSightec, Tirat-Carmel, Israel); the Sonalleve MR-HIFU (Philips Healthcare, Andover, MA, USA) is another system, approved in Europe.

\section{Selection of patients}

Correct patient selection is a fundamental process in determining technical and clinical outcome $[104,105]$. Hence, a combined clinical and imaging evaluation for each specific case is mandatory before proposing MRgFUS as a treatment option.

The primary goal of this procedures being the control of symptoms rather than the disappearance of treated lesions, only symptomatic patients can undergo MRgFUS; candidates should complete the symptom-severity score (SSS) of the Uterine Fibroid Symptoms and Quality of Life (UFS-QOL) questionnaire, assessing the intensity of symptoms caused by fibroids. Then, every patient has to be confirmed in her diagnosis of uterine fibroids through MRI, as other conditions may mimic the symptoms; at the same time, features of dominant fibroids (defined as the fibroids most likely to be responsible for symptoms), such as number, size, signal intensity and vascularization, should be evaluated.

Specifically, inclusion criteria are extended to: women in whom dominant fibroids have been diagnosed and that are compatible with the clinical presentation; women with a desire for future pregnancies; fibroids with MRI features compatible to MRgFUS treatment. The "ideal" fibroid is solitary, with a diameter $\leq 10 \mathrm{~cm}$, low signal intensity on T2W MRI, with enhancement after contrast administration; it needs to be accessible by the MRgFUS system [106].

Absolute contraindications to MRgFUS procedures include a positive pregnancy test, general contraindications to MRI (e.g. pacemakers, metallic implants, claustrophobia, etc.) or to gadolinium-based contrast agent administration, anemia $(\mathrm{Hb}<10 \mathrm{~g} / \mathrm{dl})$, a body weight greater than $115 \mathrm{Kg}$ or concomitant pathologies (such as rectal cancer, ovarian cancer, etc.) [106].

Relative contraindications are: inconsistent relationship between fibroid features and patient's symptoms; more than five symptomatic fibroids; fibroids diameter $\geq 10 \mathrm{~cm}$; pedunculated fibroids with a narrow stalk; T2-weighted hyperintense fibroids (because of high vascularization and thus "heat sink" effects); non-contrast-enhanced fibroids (because of a lack of vascularization); fibroids with gross peripheral calcifications; MRI signs of sarcomatous degeneration, requiring a surgical approach; large and thick abdominal scars on the skin surface that needs to be crossed by ultrasound (smaller scars can be shielded by cutaneous plasters); interposition of bowel loops between the abdominal wall and the fibroid, due to the risk of bowel perforation induced by cavitation phenomena within the intestinal air; fibroids with more than $50 \%$ of their volume at $>11 \mathrm{~cm}$ from the skin surface; fibroids close to the sacrum [106]. The latter three conditions are commonly considered relative contraindications, as mitigation techniques, such as bladder or rectal filling, can be employed in an attempt to shift anatomical relationships and make a MRgFUS treatment technically feasible. GnRH agonists may be administered in the three months (one shot every month) prior to treatment to decrease fibroid size $[106,107]$ or vascularity $[107,108]$. A schematic summary of factors weighing in on the selection process of patients is provided in Table 6.

\section{Technique}

After an overnight fast, the patient is admitted at the outpatient MRI suite. The patient's abdomen has to be absolutely clean, as any dirt, cream or lotion may cause skin burns during the treatment. After shaving the patient between the navel and $1 \mathrm{~cm}$ below the pubic bone, a urinary catheter is placed into the bladder and an IV line is placed for administration of conscious sedation (fentanyl, midazolam). Thus, the subject is placed prone 
Table 6: Factors weighing in on the selection process of patients for MRgFUS procedure.

\begin{tabular}{|c|c|c|c|c|}
\hline Factors & $\begin{array}{l}\text { Treatment might } \\
\text { be helpful without } \\
\text { complications }\end{array}$ & $\begin{array}{l}\text { No treatment necessaryl } \\
\text { Treatment possibly } \\
\text { harmful }\end{array}$ & $\begin{array}{l}\text { Possible countermeasures } \\
\text { to negative factors }\end{array}$ & $\begin{array}{l}\text { Relative numbers } \\
{[116,120]}\end{array}$ \\
\hline Symptoms relevance & Significant symptoms & No significant symptoms & Preventive treatment & - \\
\hline Fibroid type & Any non-pedunculated & Pedunculated & $\begin{array}{l}\text { Release of fibroid into } \\
\text { abdominal cavity never } \\
\text { documented }\end{array}$ & $\begin{array}{l}5 / 373(1.34 \%) \\
\text { Overall: } 1-5 \%\end{array}$ \\
\hline Fibroid size & $3-10 \mathrm{~cm}$ & $<3 \mathrm{~cm} ;>10 \mathrm{~cm} />300 \mathrm{ml}$ & Multiple treatments, GnRHa & $\begin{array}{l}\text { 20/373 }(5.36 \%) \\
\text { Overall: } 5-11 \%\end{array}$ \\
\hline Distance from skin & $\begin{array}{l}\text { Inside available } \\
\text { treatment area }\end{array}$ & $\begin{array}{l}>50 \% \text { outside of possible } \\
\text { treatment area }\end{array}$ & Thin gel pad; rectal filling & $2 / 373(0.53 \%)$ \\
\hline Fibroid number & $\leq 6$ & $>6$ fibroids & - & $45 / 373(12.06 \%)$ \\
\hline Distance from Bones & - & $\begin{array}{l}\text { Close to vertebrae or } \\
\text { sacrum }\end{array}$ & $\begin{array}{l}\text { Tilting beam path; rectal } \\
\text { filling; multiple, smaller } \\
\text { treatments }\end{array}$ & - \\
\hline $\begin{array}{l}\text { Obstacles along US } \\
\text { beam path }\end{array}$ & None & Scars, bone, air, bowel & $\begin{array}{l}\text { Rectal/bladder fill, beam } \\
\text { angulation }\end{array}$ & $2 / 169(1.18 \%)$ \\
\hline Fibroid vascularity & Little vascularity & Increased vascularity & $\mathrm{GnRHa}$ & - \\
\hline Beam aberration & - & $\begin{array}{l}\text { Tissue irregularities along } \\
\text { the beam path }\end{array}$ & - & - \\
\hline Adenomyosis & - & Presence of adenomyosis & Possibly treatment & $16 / 373(4.29 \%)$ \\
\hline Malignancy & - & Presence of malignancy & Surgical intervention & $19 / 373(4.29 \%)$ \\
\hline
\end{tabular}

GnRHa: Gonadotropin Releasing Hormone analog; US: Ultrasound.

onto the MRgFUS table and acoustically coupled to it by means of a gel pad that lies between the patient's abdomen and the ultrasound transducer.

The acquisition of multiple MRI sequences allows a correct treatment planning whilst taking into account potential critical factors that may contraindicate performing the procedure. Treatment is performed under continuous and active monitoring of vital signs; rectal and bladder filling (US gel and saline, respectively) is considered after the evaluation of the position and, possibly, mobility of the uterus with low-resolution fast-acquired localizer images. If patient positioning and alignment (transducer-fibroid) is considered adequate for treatment, full-resolution T2-weighted images are obtained for the planning phase. Before starting the treatment, low-energy sonications are delivered to verify the correct positioning of the treatment focus and the absorption rate of the fibroid. Once these elements are confirmed, the energy can be increased and the real treatment begins. Lastly, T1 fat-saturated gadolinium contrast-enhanced images are acquired to assess the resulting necrosis within the fibroid, calculated as the non-perfused volume (NPV) ratio, which is defined as the non-perfused tissue volume after treatment divided by the whole fibroid volume before treatment.

\section{Outcomes}

Documented outcomes have, overall, been positive with a general immediate effectiveness of treatment and hospitalization times of 1-3 days with return to full activity after 4-6 days, compared with 8-28 days, 12-37 days or more than 5 weeks with UAE, myomectomy or hysterectomy, respectively [109-111]. Most importantly, self-reported quality of life was increased with treat- ment [112]. In one study, symptomatic relief has been shown to be, respectively $86 \%$ (90/105), 93\% (92/99) and 88\% (78/89) at 3-, 6-, and 12-month follow-up [113].

One large cohort study reported re-interventions in $77 / 180(42.8 \%)$ and $96 / 162$ (59.3\%) patients at 3- and 5 -year follow-up, respectively; the use of GnRH agonists pre-treatment appears to be related to a significant reduction in re-intervention rates: $36.04 \%$ versus $48.7 \%$ at 3 -year follow-up and $51.25 \%$ versus $65.7 \%$ at 5 -year follow-up [114].

A predictive factor for the outcome of the treatment appears to be the appearance of the fibroid on MRI, with the hypointense fibroids being, in general, more responsive than the hyperintense ones. In T2w images slight enhancement was predictive of a higher NPV after treatment compared to irregular or regular enhancement, the latter type being the worst [115].

Especially when GnRH agonist therapy is administered prior to MRgFUS treatment, fibroid image characteristics seem to be of predictive value. NPVs of $85 \%$, $63 \%, 72 \%$ and $32 \%$ have been reported in one study for heterogeneously hyperintense, heterogeneously hypointense, hypointense fibroids and isointense fibroids, respectively [116].

A 24-month follow up of 359 patients showed that an increased volume ablated led to an improvement of Symptom Severity Score (SSS); the reduction in fibroid volume was sustained, meaning that the treatment was somewhat durable [102].

Undergoing MRgFUS treatment at a younger age is associated with an increased risk of additional treatments because of possible fibroid recurrence before the 
onset of menopause. There is a high risk of additional procedures in women with multiple fibroids and with larger fibroids compared to patients with single and/or small fibroids [117].

Using MRgFUS it is possible to treat only selected fibroids; with UAE, all fibroids can be treated at one time; non-treated fibroids during MRgFUS may become the cause of persistence or relapse of symptoms.

Although being previously labeled as not indicated for women who wish to have future pregnancies, several cases of spontaneous pregnancy have been reported after treatment. Rabinovici, et al. [118] reported 54 pregnancies in 51 women after treatment with MRgFUS; the average time to conception was 8 months after treatment. $41 \%$ of these resulted in life births, $28 \%$ were spontaneously aborted and $11 \%$ were electively terminated. Compared to UAE, the possibility to have a pregnancy after MRgFUS is increased [119].

\section{Complications}

As reported in a fairly large cohort study, mild to moderate pain was reported by 18 of 280 women $(6.4 \%)$ in the absence of any other significant complication. 3.9\% (11 out of 280 women) of patients experienced minor complications (UTI, urinary retention, vaginal bleeding, transient buttock pain); only 3 out of 280 women (1.1\%) experienced severe complications: one fibroid expulsion, one major skin burn requiring surgical repair, and one case of persistent neuropathy [114]; the former can, in our experience, be considered a desirable event. First-degree burns may cause some discomfort during the first week after the procedure. As with all uterine-preserving treatments, MRgFUS may bear the

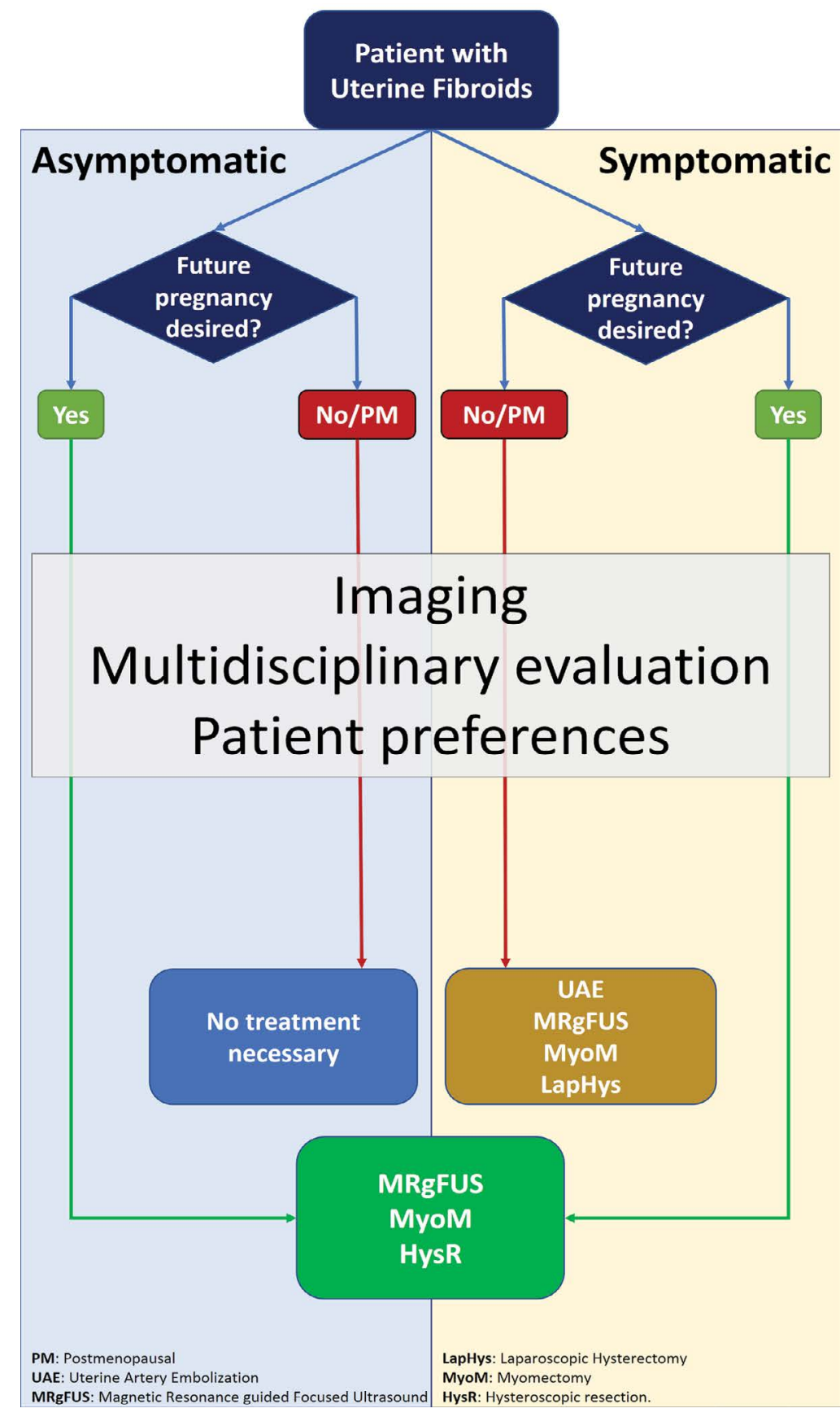

Figure 1: Decisional tree for the management of uterine fibroids. 
risk of fibroid regrowth and reappearance of symptoms. Overall, the treatment is deemed very safe.

\section{Conclusion}

The management of symptomatic uterine fibroids appears laborious and confusing because of multiple available treatment options. Uterus-sparing approaches can rely on a continuously growing range of therapeutic alternatives that have already proven their efficacy and may lead to difficulties in choosing among these for both the physician and the patient. For this reason, a multidisciplinary approach has always been advocated for, involving specialists from different areas of interest, such as the gynecologist and the interventional radiologist.

In our personal experience, a combination of clinical evaluation and imaging studies is the fundamental starting point for patient management; each symptomatic woman diagnosed with uterine fibroids should undergo a pelvic contrast MRI scan for the assessment of the fibroids' features, such as number, dimension, location, vascularity, contrast enhancement, etc. The need for a pelvic MRI in all cases unavoidably leads to a rise in management costs that does, however, not make the approach unreasonable, as the unchallenged accuracy of $\mathrm{MRI}$ in precisely describing different fibroid tissue compositions offers a fundamental guide for a correct choice of the most appropriate treatment; hence reducing the risk of treatment failures, retreatments or adverse side-effects, MRI could even bring on an effective reduction of overall individual management costs.

This initial exam should be followed by a collegial evaluation involving the gynecologist and the radiologist, and a careful counseling session with the patient, during which the specialist illustrates the most suitable therapeutic options for the specific case and investigates the patient's preferences. A general guide for the choice of the most appropriate interventional treatment is provided in Figure 1.

Given the excellent results of MRgFUS in terms of safety, non-invasiveness and potential for future childbearing, this approach is the primary proposal at our institute, especially in subjects with a desire for future pregnancies or for a conservative approach regarding the uterus: if the patient fulfills all the eligibility criteria and does not show any kind of contraindications, MRgFUS is always proposed to the patient as the first option (see Figure 1).

Among patients who cannot undergo MRgFUS or refuse treatment, we usually reserve medical therapy to women in perimenopausal age or imminently scheduled for surgical intervention; transabdominal/laparoscopic or hysteroscopic myomectomy is generally proposed to patients with a single dominant lesion and with the desire to conceive: The specific surgical access can be chosen according to the specific features of the patient and the fibroid; UAE is usually preferred for those patients who want to avoid surgery, who have multiple dominant lesions and who did not express a desire for future pregnancies.

In conclusion, a thorough knowledge of the properties of each therapeutic strategy is fundamental for a correct orientation of the specialist in the management of symptomatic uterine fibroids; the final purpose has to be the establishment of an individual-centered care system, within each woman will be addressed by the most suitable among the available treatment options.

\section{References}

1. Marret H, Fritel X, Ouldamer L, Bendifallah S, Brun JL, et al. (2012) Therapeutic management of uterine fibroid tumors: Updated French guidelines. Eur J Obstet Gynecol Reprod Biol 165: 156-164.

2. Andersson JK, Rybo G (1990) Levonorgestrel-releasing intrauterine device in the treatment of menorrhagia. $\mathrm{Br} \mathrm{J}$ Obstet Gynaecol 97: 690-694.

3. Palomba S, Orio F, Russo T, Falbo A, Tolino A, et al. (2005) Antiproliferative and proapoptotic effects of raloxifene on uterine leiomyomas in postmenopausal women. Fertil Steril 84: 154-161.

4. Bouchard $P$ (2011) Current and future medical treatments for menometrorrhagia during the premenopause. Gynecological Endocrinology 27: 1120-1125.

5. Song H, Lu D, Navaratnam K, Shi G (2013) Aromatase inhibitors for uterine fibroids. Cochrane Database Syst Rev.

6. De Leo V, la Marca A, Morgante G, Severi FM, Petraglia $F$ (2001) Administration of somatostatin analogue reduces uterine and myoma volume in women with uterine leiomyomata. Fertil Steril 75: 632-633.

7. La Marca A, Giulini S, Vito G, Orvieto R, Volpe A, et al. (2004) Gestrinone in the treatment of uterine leiomyomata: Effects on uterine blood supply. Fertil Steril 82: 1694-1696.

8. Ke LQ, Yang K, Li J, Li CM (2009) Danazol for uterine fibroids. Cochrane Database Syst Rev.

9. Lukes AS, Moore KA, Muse KN, Gersten JK, Hecht BR, et al. (2010) Tranexamic acid treatment for heavy menstrual bleeding: A randomized controlled trial. Obstet Gynecol 116: 865-875.

10. Sabry M, Halder SK, Allah ASA, Roshdy E, Rajaratnam V, et al. (2013) Serum vitamin D3 level inversely correlates with uterine fibroid volume in different ethnic groups: A cross-sectional observational study. Int J Womens Health 5: 93-100.

11. Roshdy E, Rajaratnam V, Maitra S, Sabry M, Allah A, et al. (2013) Treatment of symptomatic uterine fibroids with green tea extract: A pilot randomized controlled clinical study. Int J Womens Health 5: 477-486.

12. Conn PD, Crowley Jr M (1994) Gonadotropin-releasing hormone and its analogs. Annu Rev Med 45: 391-405.

13. Khan KN, Kitajima M, Hiraki K, Fujishita A, Nakashima M, et al. (2010) Cell proliferation effect of $\mathrm{GnRH}$ agonist on pathological lesions of women with endometriosis, adenomyosis and uterine myoma. Hum Reprod 25: 2878-2890.

14. Schlaff WD, Zerhouni EA, Huth JA, Chen J, Damewood MD, et al. (1989) A placebo-controlled trial of a depot gonadotropin-releasing hormone analogue (leuprolide) in the treatment of uterine leiomyomata. Obstet Gynecol 74: 856-862. 
15. Filicori M, Hall DA, Loughlin JS, Rivier J, Vale W, et al. (1983) A conservative approach to the management of uterine leiomyoma: Pituitary desensitization by a luteinizing hormone-releasing hormone analogue. Am J Obstet Gynecol 147: 726-727.

16. van de Ven J, Donker TH, Blankenstein MA, Thijssen JH (2002) Differential effect of gonadotropin-releasing hormone analogue treatment on estrogen levels and sulfatase activity in uterine leiomyoma and myometrium. Fertil Steril 77: 1227-1232.

17. Deligdisch L, Hirschmann S, Altchek A (1997) Pathologic changes in gonadotropin releasing hormone agonist analogue treated uterine leiomyomata. Fertil Steril 67: 837-841.

18. Friedman AJ, Hoffman DI, Comite F, Browneller RW, Miller JD (1991) Treatment of leiomyomata uteri with leuprolide acetate depot: A double-blind, placebo-controlled, multicenter study. Obstet Gynecol 77: 720-725.

19. Surrey ES (2010) Gonadotropin-releasing hormone agonist and add-back therapy: What do the data show? Curr Opin Obstet Gynecol 22: 283-288.

20. Kamath MS, Kalampokas EE, Kalampokas TE (2014) Use of $\mathrm{GnRH}$ analogues pre-operatively for hysteroscopic resection of submucous fibroids: A systematic review and meta-analysis. Eur J Obstet Gynecol Reprod Biol 177: 1118.

21. Spitz IM (2009) Clinical utility of progesterone receptor modulators and their effect on the endometrium. Curr Opin Obstet Gynecol 21: 318-324.

22. Sasaki H, Ohara N, Xu Q, Wang J, DeManno DA, et al. (2007) A novel selective progesterone receptor modulator asoprisnil activates tumor necrosis factor-related apoptosis-inducing ligand (TRAIL)-mediated signaling pathway in cultured human uterine leiomyoma cells in the absence of comparable effects on myometrial cells. J Clin Endocrinol Metab 92: 616-623.

23. Chwalisz K, Larsen L, Mattia-Goldberg C, Edmonds A, Elger W, et al. (2007) A randomized, controlled trial of asoprisnil, a novel selective progesterone receptor modulator, in women with uterine leiomyomata. Fertil Steril 87: 13991412.

24. Nieman LK, Blocker W, Nansel T, Mahoney S, Reynolds $\mathrm{J}$, et al. (2011) Efficacy and tolerability of CDB-2914 treatment for symptomatic uterine fibroids: A randomized, double-blind, placebo-controlled, phase Ilb study. Fertil Steril 95: 767-772.e1-2

25. Donnez J, Courtoy GE, Donnez O, Dolmans MM (2018) Ulipristal acetate for the management of large uterine fibroids associated with heavy bleeding: A review. Reprod Biomed Online 37: 216-223.

26. EMA (2018) Assement report on provisional measures.

27. Donnez J, Tomaszewski J, Vázquez F, Bouchard P, Lemieszczuk B, et al. (2012) Ulipristal acetate versus leuprolide acetate for uterine fibroids. New England Journal of Medicine 366: 421-432.

28. Mutter GL, Bergeron C, Deligdisch L, Ferenczy A, Glant $M$, et al. (2008) The spectrum of endometrial pathology induced by progesterone receptor modulators. Mod Pathol 21: $591-598$.

29. Eder S, Baker J, Gersten J, Mabey RG, Adomako TL (2013) Efficacy and safety of oral tranexamic acid in women with heavy menstrual bleeding and fibroids. Womens Health (Lond) 9: 397-403.
30. Naoulou B, Tsai MC (2012) Efficacy of tranexamic acid in the treatment of idiopathic and non-functional heavy menstrual bleeding: A systematic review. Acta Obstet Gynecol Scand 91: 529-537.

31. Stewart EA (2015) Clinical practice: Uterine fibroids. N Engl J Med 372: 1646-1655.

32. Sangkomkamhang US, Lumbiganon $\mathrm{P}$, Laopaiboon $\mathrm{M}$, Mol BW (2013) Progestogens or progestogen-releasing intrauterine systems for uterine fibroids. Cochrane Database Syst Rev CD008994.

33. Lethaby AE, Cooke I, Rees M (2005) Progesterone or progestogen-releasing intrauterine systems for heavy menstrual bleeding. Cochrane Database Syst Rev CD002126.

34. Zapata LB, Whiteman MK, Tepper NK, Jamieson DJ, Marchbanks PA, et al. (2010) Intrauterine device use among women with uterine fibroids: A systematic review. Contraception 82: 41-55.

35. Sayed GH, Zakherah MS, El-Nashar SA, Shaaban MM (2011) A randomized clinical trial of a levonorgestrel-releasing intrauterine system and a low-dose combined oral contraceptive for fibroid-related menorrhagia. Int J Gynaecol Obstet 112: 126-130.

36. Socolov D, Blidaru I, Tamba B, Miron N, Boiculese L, et al. (2011) Levonorgestrel releasing-intrauterine system for the treatment of menorrhagia and/or frequent irregular uterine bleeding associated with uterine leiomyoma. Eur J Contracept Reprod Health Care 16: 480-487.

37. Kriplani A, Awasthi D, Kulshrestha V, Agarwal N (2012) Efficacy of the levonorgestrel-releasing intrauterine system in uterine leiomyoma. Int J Gynaecol Obstet 116: 35-38.

38. Tasci $Y$, Caglar GS, Kayikcioglu F, Cengiz H, Yagci B, et al. (2009) Treatment of menorrhagia with the levonorgestrel releasing intrauterine system: Effects on ovarian function and uterus. Arch Gynecol Obstet 280: 39-42.

39. Wrona W, Stępniak A, Czuczwar P (2017) The role of levonorgestrel intrauterine systems in the treatment of symptomatic fibroids. Prz Menopauzalny 16: 129-132.

40. Pérez-López FR, Ornat L, Ceausu I, Depypere H, Erel CT, et al. (2014) EMAS position statement: Management of uterine fibroids. Maturitas 79: 106-116.

41. Qin J, Yang T, Kong F, Zhou Q (2013) Oral contraceptive use and uterine leiomyoma risk: A meta-analysis based on cohort and case-control studies. Arch Gynecol Obstet 288: 139-148.

42. Ichigo S, Takagi H, Matsunami K, Suzuki N, Imai A (2011) Beneficial effects of dienogest on uterine myoma volume: A retrospective controlled study comparing with gonadotropin-releasing hormone agonist. Arch Gynecol Obstet 284: 667-670.

43. Venkatachalam S, Bagratee JS, Moodley J (2004) Medical management of uterine fibroids with medroxyprogesterone acetate (Depo Provera): A pilot study. J Obstet Gynaecol 24: $798-800$

44. Friedman AJ, Daly M, Juneau-Norcross M, Fine C, Rein MS (1992) Recurrence of myomas after myomectomy in women pretreated with leuprolide acetate depot or placebo. Fertil Steril 58: 205-208.

45. Harrison-Woolrych M, Robinson R (1995) Fibroid growth in response to high-dose progestogen. Fertil Steril 64: 191192.

46. Sumitani $H$, Shozu M, Segawa T, Murakami K, Yang HJ, et al. (2000) In situ estrogen synthesized by aromatase P450 
in uterine leiomyoma cells promotes cell growth probably via an autocrine/intracrine mechanism. Endocrinology 141: 3852-3861.

47. Ishikawa H, Reierstad S, Demura M, Rademaker AW, Kasai $\mathrm{T}$, et al. (2009) High aromatase expression in uterine leiomyoma tissues of African-American women. J Clin Endocrinol Metab 94: 1752-1756.

48. Parsanezhad ME, Azmoon M, Alborzi S, Rajaeefard A, Zarei A, et al. (2010) A randomized, controlled clinical trial comparing the effects of aromatase inhibitor (letrozole) and gonadotropin-releasing hormone agonist (triptorelin) on uterine leiomyoma volume and hormonal status. Fertil Steril 93: 192-198.

49. Talaulikar VS (2017) Medical therapy for fibroids: An Overview. Best Practice \& Research Clinical Obstetrics \& Gynaecology 46: 48-56.

50. Deng L, Wu T, Chen XY, Xie L, Yang J (2012) Selective estrogen receptor modulators (SERMs) for uterine leiomyomas. Cochrane Database Syst Rev.

51. Sohn GS, Cho S, Kim YM, Cho CH, Kim MR, et al. (2018) Current medical treatment of uterine fibroids. Obstet Gynecol Sci 61: 192-201.

52. Bonney $\vee(1931)$ The technique and results of myomectomy. Lancet 217: 171-177.

53. Semm K (1979) New methods of pelviscopy (gynecologic laparoscopy) for myomectomy, ovariectomy, tubectomy and adnectomy. Endoscopy 11: 85-93.

54. Buckley VA, Nesbitt-Hawes EM, Atkinson P, Won HR, Deans R, et al. (2015) Laparoscopic myomectomy: Clinical outcomes and comparative evidence. J Minim Invasive Gynecol 22: 11-25.

55. Landi S, Zaccoletti R, Ferrari L, Minelli L (2001) Laparoscopic myomectomy: Technique, complications, and ultrasound scan evaluations. J Am Assoc Gynecol Laparosc 8: 231-240.

56. Radosa MP, Winzer H, Mothes AR, Camara O, Diebolder $\mathrm{H}$, et al. (2012) Laparoscopic myomectomy in peri-and post-menopausal women is safe, efficacious and associated with long-term patient satisfaction. Eur J Obstet Gynecol Reprod Biol 162: 192-196.

57. Yoo EH, Lee PI, Huh CY, Kim DH, Lee BS, et al. (2007) Predictors of leiomyoma recurrence after laparoscopic myomectomy. J Minim Invasive Gynecol 14: 690-697.

58. Nezhat FR, Roemisch M, Nezhat CH, Seidman DS, Nezhat CR (1998) Recurrence rate after laparoscopic myomectomy. J Am Assoc Gynecol Laparosc 5: 237-240.

59. Sizzi O, Rossetti A, Malzoni M, Minelli L, La Grotta F, et al. (2007) Italian multicenter study on complications of laparoscopic myomectomy. J Minim Invasive Gynecol 14: 453462.

60. Samejima T, Koga K, Nakae H, Wada-Hiraike O, Fujimoto A, et al. (2015) Identifying patients who can improve fertility with myomectomy. Eur J Obstet Gynecol Reprod Biol 185: 28-32.

61. Luca Ferrario, Pietro Zerbi, Maria Rachele Angiolini, Alberto Agarossi, Eliana Riggio, et al. (2018) Leiomyomatosis peritonealis disseminata: A case report of recurrent presentation and literature review. Int J Surg Case Rep 49: 25-29.

62. Jin C, Hu Y, Chen XC, Zheng FY, Lin F, et al. (2009) Laparoscopic versus open myomectomy-a meta-analysis of randomized controlled trials. Eur J Obstet Gynecol Reprod Biol 145: 14-21.
63. Theben JU, Schellong AR, Altgassen C, Kelling K, Schneider S, et al. (2013) Unexpected malignancies after laparoscopic-assisted supracervical hysterectomies (LASH): An analysis of 1,584 LASH cases. Arch Gynecol Obstet 287: 455-462.

64. Bhave Chittawar P, Franik S, Pouwer AW, Farquhar C (2014) Minimally invasive surgical techniques versus open myomectomy for uterine fibroids. Cochrane Database Syst Rev 10: CD004638.

65. Parker WH, Rodi IA (1994) Patient selection for laparoscopic myomectomy. J Am Assoc Gynecol Laparosc 2: 23-26.

66. Sinha R, Hegde A, Warty N, Patil N (2003) Laparoscopic excision of very large myomas. The Journal of the American Association of Gynecologic Laparoscopists 10: 461468.

67. Brölmann H, Tanos V, Grimbizis G, Ind T, Philips K, et al. (2015) Options on fibroid morcellation: A literature review. Gynecol Surg 12: 3-15.

68. Rousseau M, Morel A, Dechoux S, Bouet PE, Catala L, et al. (2018) Can the risks associated with uterine sarcoma morcellation really be prevented? Overview of the role of uterine morcellation in 2018. J Gynecol Obstet Hum Reprod.

69. Munro MG, Critchley HO, Broder MS, Fraser IS, FIGO Working Group on Menstrual Disorders (2011) FIGO classification system (PALM-COEIN) for causes of abnormal uterine bleeding in nongravid women of reproductive age. Int J Gynaecol Obstet 113: 3-13.

70. Pritts EA, Parker WH, Olive DL (2009) Fibroids and infertility: An updated systematic review of the evidence. Fertil Steril 91: 1215-1223.

71. Friedman JA, Wong JMK, Chaudhari A, Tsai S, Milad MP (2018) Hysteroscopic myomectomy: A comparison of techniques and review of current evidence in the management of abnormal uterine bleeding. Curr Opin Obstet Gynecol 30: 243-251.

72. Casadio P, Guasina F, Morra C, Talamo MT, Leggieri C, et al. (2016) Hysteroscopic myomectomy: Techniques and preoperative assessment. Minerva Ginecol 68: 154-166.

73. Ravina JH, Herbreteau D, Ciraru-Vigneron N, Bouret JM, Houdart E, et al. (1995) Arterial embolisation to treat uterine myomata. Lancet 346: 671-672.

74. Goodwin SC, Spies JB (2009) Uterine fibroid embolization. N Engl J Med 361: 690-697.

75. Bulman JC, Ascher SM, Spies JB (2012) Current concepts in uterine fibroid embolization. Radiographics 32: 17351750.

76. Gupta JK, Sinha A, Lumsden MA, Hickey M (2006) Uterine artery embolization for symptomatic uterine fibroids. Cochrane Database Syst Rev.

77. van Overhagen H, Reekers JA (2015) Uterine artery embolization for symptomatic leiomyomata. Cardiovasc Intervent Radiol 38: 536-542.

78. Parthipun A, Taylor J, Manyonda I, Belli AM (2010) Does size really matter? Analysis of the effect of large fibroids and uterine volumes on complication rates of uterine artery embolisation. Cardiovasc Intervent Radiol 33: 955-959.

79. Smeets AJ, Nijenhuis RJ, van Rooij WJ, Weimar EA, Boekkooi PF, et al. (2010) Uterine artery embolization in patients with a large fibroid burden: Long-term clinical and MR follow-up. Cardiovasc Intervent Radiol 33: 943-948. 
80. AAGL, AMIG Worldwide (2012) AAGL practice report: Practice guidelines for the diagnosis and management of submucous leiomyomas. J Minim Invasive Gynecol 19: 152-171.

81. Gynaecologists RCoOa (2013) Clinical recommendations on the use of uterine artery embolization (UAE) in the management of fibroid. ( $3^{\text {rd }}$ edn), RCOG and RCR, London.

82. Khan AT, Shehmar M, Gupta JK (2014) Uterine fibroids: Current perspectives. Int J Womens Health 6: 95-114.

83. Das R, Champaneria R, Daniels JP, Belli AM (2014) Comparison of embolic agents used in uterine artery embolisation: A systematic review and meta-analysis. Cardiovasc Intervent Radiol 37: 1179-1190.

84. Worthington-Kirsch R, Spies JB, Myers ER, Mulgund J, Mauro M, et al. (2005) The Fibroid Registry for outcomes data (FIBROID) for uterine embolization: Short-term outcomes. Obstet Gynecol 106: 52-59.

85. Spies JB, Myers ER, Worthington-Kirsch R, Mulgund J, Goodwin S, et al. (2005) The FIBROID Registry: symptom and quality-of-life status 1 year after therapy. Obstet Gynecol 106: 1309-1318.

86. Dutton S, Hirst A, McPherson K, Nicholson T, Maresh M (2007) A UK multicentre retrospective cohort study comparing hysterectomy and uterine artery embolisation for the treatment of symptomatic uterine fibroids (HOPEFUL study): Main results on medium-term safety and efficacy. BJOG 114: 1340-1351.

87. Lanocita R, Frigerio L, Patelli G, Di Tolla G, Spreafico C (1999) A fatal complication of percutaneous transcatheter embolization for treatment of uterine fibroids. 2nd International symposium on the embolization of uterine myomata, 17-18.

88. de Blok S, de Vries C, Prinssen HM, Blaauwgeers HL, Jorna-Meijer LB (2003) Fatal sepsis after uterine artery embolization with microspheres. J Vasc Interv Radiol 14: 779-783.

89. Vashisht A, Studd J, Carey A, Burn P (1999) Fatal septicaemia after fibroid embolisation. Lancet 354: 307-308.

90. Toor SS, Jaberi A, Macdonald DB, Mclnnes MD, Schweitzer $\mathrm{ME}$, et al. (2012) Complication rates and effectiveness of uterine artery embolization in the treatment of symptomatic leiomyomas: A systematic review and meta-analysis. AJR Am J Roentgenol 199: 1153-1163.

91. van der Kooij SM, Hehenkamp WJ, Volkers NA, Birnie E, Ankum WM, et al. (2010) Uterine artery embolization vs hysterectomy in the treatment of symptomatic uterine fibroids: 5-year outcome from the randomized EMMY trial. Am J Obstet Gynecol 203: 105.e1-105.e13.

92. Moss J, Cooper K, Khaund A, Murray LS, Murray GD, et al. (2011) Randomised comparison of uterine artery embolisation (UAE) with surgical treatment in patients with symptomatic uterine fibroids (REST trial): 5 -year results. BJOG 118: 936-944.

93. Wu O, Briggs A, Dutton S, Hirst A, Maresh M, et al. (2007) Uterine artery embolisation or hysterectomy for the treatment of symptomatic uterine fibroids: A cost-utility analysis of the HOPEFUL study. BJOG 114: 1352-1362.

94. Manyonda IT, Bratby M, Horst JS, Banu N, Gorti M, et al. (2012) Uterine artery embolization versus myomectomy: Impact on quality of life-results of the FUME (Fibroids of the Uterus: Myomectomy versus Embolization) Trial. Cardiovasc Intervent Radiol 35: 530-536.

95. Vetter S, Schultz F, Strecker EP, Zoetelief J (2004) Patient radiation exposure in uterine artery embolization of leiomyomata: Calculation of organ doses and effective dose. Eur Radiol 14: 842-848.
96. McPherson K, Manyonda I, Lumsden MA, Belli AM, Moss $\mathrm{J}$, et al. (2014) A randomised trial of treating fibroids with either embolisation or myomectomy to measure the effect on quality of life among women wishing to avoid hysterectomy (the FEMME study): Study protocol for a randomised controlled trial. Trials 15: 468.

97. Mara M, Maskova J, Fucikova Z, Kuzel D, Belsan T, et al. (2008) Midterm clinical and first reproductive results of a randomized controlled trial comparing uterine fibroid embolization and myomectomy. Cardiovasc Intervent Radiol 31: 73-85.

98. Hehenkamp WJ, Volkers NA, Broekmans FJ, de Jong FH, Themmen AP, et al. (2007) Loss of ovarian reserve after uterine artery embolization: A randomized comparison with hysterectomy. Hum Reprod 22: 1996-2005.

99. Arthur R, Kachura J, Liu G, Chan C, Shapiro H (2014) Laparoscopic myomectomy versus uterine artery embolization: Long-term impact on markers of ovarian reserve. J Obstet Gynaecol Can 36: 240-247.

100. Napoli A, Anzidei M, Ciolina F, Marotta E, Cavallo Marincola $B$, et al. (2013) MR-guided high-intensity focused ultrasound: Current status of an emerging technology. Cardiovasc Intervent Radiol 36: 1190-1203.

101. Simon CJ, Dupuy DE, Mayo-Smith WW (2005) Microwave ablation: Principles and applications 1. Radiographics 25: S69-S83.

102. Ciolina F, Manganaro L, Scipione R, Napoli A (2016) Alternatives to surgery for the treatment of myomas. Minerva Ginecol 68: 364-379.

103. Hynynen K, Freund WR, Cline HE, Chung AH, Watkins RD, et al. (1996) A clinical, noninvasive, MR imaging-monitored ultrasound surgery method. Radiographics 16: 185-195.

104. Stewart EA, Rabinovici J, Tempany CM, Inbar Y, Regan L, et al. (2006) Clinical outcomes of focused ultrasound surgery for the treatment of uterine fibroids. Fertil Steril 85: 22-29.

105. Lénárd ZM, McDannold NJ, Fennessy FM, Stewart EA, Jolesz FA, et al. (2008) Uterine leiomyomas: MR imaging-guided focused ultrasound surgery-imaging predictors of success 1. Radiology 249: 187-194.

106. Yoon S-W, Lee C, Cha SH, Yu JS, Na YJ, et al. (2008) Patient selection guidelines in MR-guided focused ultrasound surgery of uterine fibroids: A pictorial guide to relevant findings in screening pelvic MRI. Eur Radiol 18: 2997-3006.

107. Fennessy FM, Tempany CM, McDannold NJ, So MJ, Hesley G, et al. (2007) Uterine leiomyomas: MR imaging-guided focused ultrasound surgery-results of different treatment protocols 1 . Radiology 243: 885-893.

108. Cura M, Cura A, Bugnone A (2006) Role of magnetic resonance imaging in patient selection for uterine artery embolization. Acta Radiologica 47: 1105-1114.

109. Pron G, Cohen M, Soucie J, Garvin G, Vanderburgh L, et al. (2003) The Ontario Uterine Fibroid Embolization Trial. Part 1. Baseline patient characteristics, fibroid burden, and impact on life. Fertil Steril 79: 112-119.

110. Stewart EA, Gostout B, Rabinovici J, Kim HS, Regan L, et al. (2007) Sustained relief of leiomyoma symptoms by using focused ultrasound surgery. Obstet Gynecol 110: 279-287.

111. Taran F, Tempany C, Regan L, Inbar Y, Revel A, Stewart EA (2009) Magnetic resonance-guided focused ultrasound (MRgFUS) compared with abdominal hysterectomy for treatment of uterine leiomyomas. Ultrasound in Obstetrics \& Gynecology 34: 572-578. 
112. Kamp J, David M, Scheurig-Muenkler C, Hengst S, Beck A (2013) Clinical outcome of magnetic-resonance-guided focused ultrasound surgery (MRgFUS) in the treatment of symptomatic uterine fibroids. Rofo 185: 136-143.

113. Gorny KR, Woodrum DA, Brown DL, Henrichsen TL, Weaver AL, et al. (2011) Magnetic resonance-guided focused ultrasound of uterine leiomyomas: Review of a 12-month outcome of 130 clinical patients. J Vasc Interv Radiol 22: 857-864.

114. Quinn S, Vedelago J, Gedroyc W, Regan L (2014) Safety and five-year re-intervention following magnetic resonance-guided focused ultrasound (MRgFUS) for uterine fibroids. Eur J Obstet Gynecol Reprod Biol 182: 247-251.

115. Zhao W-P, Chen J-Y, Zhang L, Li Q, Qin J, et al. (2013) Feasibility of ultrasound-guided high intensity focused ultrasound ablating uterine fibroids with hyperintense on T2-weighted MR imaging. Eur J Radiol 82: e43-e49.

116. Bryant K, LeBlang S (2015) MRI characterization of uterine fibroids may predict success of $\mathrm{GnRH}$ agonist therapy prior to magnetic resonance focused ultrasound (MRgFUS) treatment. Journal of Therapeutic Ultrasound 3: 0101.

117. Spies JB, Bruno J, Czeyda-Pommersheim F, Magee ST, Ascher SA, et al. (2005) Long-term outcome of uterine artery embolization of leiomyomata. Obstet Gynecol 106: 933-939.

118. Rabinovici J, David M, Fukunishi H, Morita Y, Gostout BS, et al. (2010) Pregnancy outcome after magnetic resonance-guided focused ultrasound surgery (MRgFUS) for conservative treatment of uterine fibroids. Fertil Steril 93: 199-209.

119. Froeling V, Meckelburg K, Schreiter N, Scheurig-Muenkler C, Kamp J, et al. (2013) Outcome of uterine artery embolization versus MR-guided high-intensity focused ultrasound treatment for uterine fibroids: Long-term results. Eur J Radiol 82: 2265-2269.

120. Behera MA, Leong M, Johnson L, Brown H (2010) Eligibility and accessibility of magnetic resonance-guided focused ultrasound (MRgFUS) for the treatment of uterine leiomyomas. Fertil Steril 94: 1864-1868. 